\title{
What is the sure way to understand wild animals?
}

\begin{abstract}
This paper aims to give the definition of wildlife ecology, conservation and management. How can we understand wild animals? The sure way to understand wild animals is to study their ecology. A comprehensive knowledge of their ecology will definitely promote our understanding about them. Ecology can be defined as the scientific study of the connections that determine the distribution and abundance of organisms. Conservation can be defined as a rational use of natural resources. It is an effort to maintain and use natural resources wisely in an attempt to ensure that those resources will be available for future generations. Therefore, wildlife ecology, conservation and management can be defined as a function of parameters under consideration within the management regime. Therefore, the sure way to understand wild animals is to study their ecology.
\end{abstract}

Volume 3 Issue 5 - 2018

\author{
Egwumah FA \\ Department of Wildlife and Range Management, University of \\ Agriculture Makurdi, Benue State, Nigeria
}

Correspondence: Egwumah FA, Department of Wildlife and Range Management, University of Agriculture Makurdi, Benue State, Nigeria, Tel +2347064621278,

Email egwumahattah@gmail.com

Received: December 20, 2017 | Published: September 26, 2018

Keywords: wildlife, ecology, conservation, management, resources

\section{Introduction}

First and foremost Wildlife can be defined as free- ranging undomesticated animals that could be hunted basically for sport hunting during leisure time or food ${ }^{1}$ and they are also considered to be vertebrates ${ }^{2}$ (animals with a backbone). There is a clear distinction between organisms that are called wildlife from other vertebrates' especially lower animals and plants. Looking at it from a professional perspective, vertebrates comprises of birds and mammals. So many things took place in the discipline of wildlife management right from time immemorial resulting to new definitions of wildlife based on a more holistic perspective ${ }^{3}$ in the 1960s. The Endangered Species Act of 1973 acknowledged fish and wildlife as an associate of the animal kingdom without reservation, including any mammal, bird, fish, amphibian, reptile, mollusk, crustacean, arthropod, or other invertebrates. ${ }^{3}$ This identification actually propelled many states at the same time to embark on nongame programmes with the main purpose of managing protected, endangered or threatened and hunted wildlife populations with respect to the definition of fish and wildlife provided it is enshrined in the Endangered Species Act. From a very large billboard, wildlife should include all animals and their associated habitats. This paper aims to give the definition of wildlife ecology, conservation and management. How can we understand wild animals?

The sure way to understand wild animals is to study their ecology. A comprehensive knowledge of their ecology will definitely promote our understanding about them. We can understand the ecology of lovebirds Agapornis pullaria if and only if we study the food they eat, such as rice, maize and groundnut. Apart that, their distribution, abundance and habitat preference ${ }^{4}$ will also give us more information on their ecology. Therefore, wildlife management is all about habitat management and living organisms that are living out rightly from the direct control of man are considered to be wildlife, cultured plants and animals are inclusive. It is not correct to limit wildlife to some selected organisms; this is due to common utilization, public opinion, funding and past records. The aforementioned factors have resulted to pragmatic definition of wildlife as animals that are undomesticated and free ranging vertebrates. Continues a research and management pain with public out cry has stimulated definition of wildlife to focus on birds and mammals. Another sad story is the introduction of exotic species. Exotic species usually have their disadvantages because they will definitely compete with the indigenous plants and animals. This may occur either accidentally or intentionally as the case may be but, it comes with its advantages and disadvantages. However, exotic species are also included in the definition of wildlife over the years.

Ecology can be defined as the scientific study of the connections that determine the distribution and abundance of organisms. ${ }^{5}$ Predicting and maintaining or altering the distribution and abundance of various organisms are the paramount goals of natural resource management; for this reason, the successful management of natural ecosystems solely depends on adequate ecological knowledge. ${ }^{6}$ However, Wildlife ecology is a field that studies animal species, especially animal populations, and with emphasis in identify strategies in which those populations can be assisted. Basically, some wildlife ecology programs may be centred on interactions between animals and man, while others will study animals in all ramifications. The main responsibility of an ecologist is to promote healthy animal conservation and this can be achieved if and only if the ecologist is interested in the animals and habitats. It simply means, the ecologist must study both the animals and their habitat in order to obtained comprehensive result. Apart from that, ethology can also be used. Ethology is the study of animal behaviour to determine natural responses of animals to different environmental stimuli. Some studies are carried out in laboratory conditions to bring out measured responses. Therefore, ethology integrates laboratory and field studies which has strong relationship with other sciences such as ecology, environmental science, neurology, physiology, psychology and evolution.

The study of animal behavior begins with understanding how an animal's physiology and anatomy are integrated with its behavior. Both external and internal stimuli prompt behaviors-external information (e.g., threats from other animals, sounds, smells) or weather and internal information (e.g., hunger, fear). Understanding how genes and the environment come together to shape animal behavior is also an important underpinning of the field. Genes capture the evolutionary responses of prior populations to selection on behavior. Environmental flexibility gives animals the opportunity to adjust to changes during their own lifetime which stimulate conservation.

Conservation can be defined as a rational use of natural resources. It is an effort to maintain and use natural resources wisely in an 
attempt to ensure that those resources will be available for future generations. Wise use of resources may vary from one location to another depending on the case scenario. For example, managing a population of animals by hunting is a rational use of resources. This rational use of natural resources may lead to extinction, if not properly guided. Wildlife management can be defined as the pains directed toward wild animal populations in association to their habitat, which include habitat manipulations, basically to meet some particular human objective. It may also be defined as the practice of finding equilibrium between the needs of wild animals and that of the populace using systematic proceedings. This can be achieved if and only if their ecology is properly studied.

\section{Conclusion}

The nomenclature wildlife ecology, conservation and management have undergone lots of modifications over the years. Therefore, wildlife ecology, conservation and management can be defined as a function of parameters under consideration within the management regime. Therefore, the sure way to understand wild animals is to study their ecology.

\section{Acknowledgements}

None.

\section{Conflict of interest}

Author declares that there is no conflict of interest.

\section{References}

1. Ralpha AE, Allen EW, Pran V. Raising Game Birds. USA: University of California, Divsion of Agriculture and Natural-Resources. A publication of $8155 ; 2007$.

2. Gregor S. Born to fly-Migratory and strategies and stopover ecology in the European Wadden Sea of a long-distance migrant, the Bar-tailed Godwit Limosa lapponica. 2003

3. Greg Yarrow. Wildlife and Wildlife Management Clemson Extension Factsheet 36. 2009.

4. Egwumah FA, Egwumah PO, Agbelusi EA. Ecology, Trade and Conservation of Lovebird Agapornis pullaria. LAP Lambert: Academic Publishing Germany; 2014. 1-111.

5. Eric Laferrière, Peter $\mathrm{J}$ Stoett. International Relations Theory and Ecological Thought: Towards a Synthesis. Routledge. 2003; p. 25.

6. Hammond H. Maintaining Whole Systems on the Earth's Crown: Ecosystem-based Conservation Planning for the Boreal Forest. Slocan Park, BC: Silva Forest Foundation; 2009. p. 380. 